\title{
Effect of Banana Waste Biochar on Physiological Responses and Growth of Seashore Paspalum
}

\author{
Dounia Fetjah ${ }^{1 *}$, Lalla Fatima Ezzahra Ainlhout ${ }^{2}$, Bouchaib Ihssane ${ }^{3}$, Laila Bouqbis ${ }^{2 *}$ \\ 1 Laboratory of Biotechnology, Materials and Environment, Faculty of Sciences, Ibn Zohr University, Agadir, Morocco \\ ${ }^{2}$ Laboratory of Biotechnology, Materials and Environment, Faculty of Applied Sciences, Ibn Zohr University, \\ Ait Melloul, Morocco \\ ${ }^{3}$ Laboratory of Applied Organic Chemistry, Faculty of Sciences and Techniques, Sidi Mohamed Ben Abdellah \\ University, Fez, Morocco \\ *Corresponding author's email: fetjahdounia194@gmail.com; laila.bouqbis@gmail.com
}

\begin{abstract}
The current study aimed to evaluate the effect of banana waste biochar on the physiological traits and growth of Paspalum vaginatum under three water treatments $(100 \%, 80 \%$, and $60 \%$ of the water holding capacity (WHC) of the soil). A plastic pot experiment was done for the germination of paspalum vaginatum. The treatments were the addition of compost, banana waste biochar, or banana waste biochar and compost combination to the soil. We used multiple factor analysis (MFA) to reveal the relationship between the effect of banana waste biochar and the three water regimes on physiological data. The findings revealed that banana waste biochar had an important impacts on all traits under various water supply conditions. The photon yield of PSII of control treatment at three water regimes had the lowest response compared to amended treatments. Changes were observed in chlorophyll pigment among different treatments.
\end{abstract}

Keywords: banana waste biochar, MFA study, physiological responses, plant growth.

\section{INTRODUCTION}

In recent years, millions of dollars have been invested to provide top-tier and luxury Moroccan golf courses. Each turfgrass depends upon daily irrigation to ensure proper quality and performance. Indeed, irrigation requirements cannot be easily satisfied by communities due to limited water resources [Carrow, 1995; Katuwal et al., 2020]. For instance, Agadir is a city located in the south of the kingdom, characterized by its semi-arid and arid climate, as well as known for its agricultural activities, fisheries, and its golf courses, which are flocking the tourist around the world. The lack of water is a problem that affects its different fields. Besides, the rise in water supply costs creates new financial challenges for the management of irrigated turf areas [Dean et al., 1996]. This fact has made scientists think of new technologies to irrigate more efficiently and sustainably, to achieve new goals by managing water resources in the region.
Recent restrictions on irrigating golf courses by treated wastewater had imposed by the government can further exacerbate drought issues on turfgrasses, however, this technique is still limited by a technical and financial problem [Frascari et al., 2018]. Yet, a crucial approach was proposed for reducing water issues and degraded soils in this region which is amending golf courses soils by biochar. For a long time ago, biochar has been recognized and inspired as terra preta [Bezerra et al., 2019]. Indeed, its application for soils has been discussed as an alternative to the degraded and damaged area. It is used as an amendment due to its benefits in increasing the availability of nutrients and water in soils. Moreover, it helps to enhance the porosity of soils, as a result, enhancing water retention capacity [Rasa et al., 2018].

In our work, we choose Paspalum vaginatum despite its virtues, and its resistance to salinization, drought, and another factor of stress. Known also by the nomination of seashore paspalum or Paspalum vaginatum Swartz. It is largely used on 
athletic fields, golf courses, and landscape areas in tropical and subtropical areas. Seashore paspalum had shown its ability to resist the severe weather and surviving in the winter in subtropical regions [Ibitayo et al., 1981].

In that concern, a pot experiment was conducted to assess the banana waste biochar on Paspalum vaginatum using seven levels of organic amendment addition $(0 \%, 2 \%$ compost (2C), 2\% biochar (2B), 3\% compost (3C), 3\% biochar (3B), $4 \%$ compost-biochar (4BC), $6 \%$ compost-biochar $(6 \mathrm{BC}))$ to a loam poor soil and three water treatments $(60 \%, 80 \%$ and $100 \%$ of the water holding capacity of the control). Furthermore, several qualitative and quantitative factors intervene simultaneously in this study in order to extract useful information. Thus, multiple factorial analysis (MFA) was used to identify relationships among the organic amendments addition on seashore paspalum growth based on data obtained from photosynthesis, chlorophyll a, chlorophyll b, carotenoids, fluorescence data. The aim of this article was (1) to determine whether banana waste biochar application can improve the negative effect of water deficit in Paspalum vaginatum; (2) determine the best combination of banana waste biochar, compost, and soil required for the greatest benefit to the physiological features of the Paspalum vaginatum and (3) to help golf courses in the Souss Massa region to optimize the use of water in golf courses by keeping the same characteristics of paspalum, as well as increasing the quality of the degraded soils in the region under the arid climate.

\section{MATERIALS AND METHODS}

\section{Experiment design}

The banana waste biochar was produced at $201{ }^{\circ} \mathrm{C}$ according to the method elaborated by Bouqbis and Fetjah [Bouqbis et al., 2016; Fetjah et al., 2021].

The soil was collected, before sowing, from the top layer $(0-20 \mathrm{~cm})$ of a loam soil from a forest field plot in Agadir city, Morocco. Immediately after sampling, the soil was air-dried and stored until the start of the experiment. The soil particle distribution was sieved at a $2 \mathrm{~mm}$ mesh screen before application. Soil pH was 8.62, the soil contains $32.77 \%$ of coarse silt, $18.05 \%$ of fine silt, $9.65 \%$ of clay, $9.63 \%$ of coarse sand, $29.91 \%$ of fine sand. For the elemental composition: $0.046 \%$ of total nitrogen $\mathrm{Nt}$, $0.110 \%$ of $\mathrm{P}_{2} \mathrm{O}_{5}, 6.24 \%$ of total organic matter MOt, $3.62 \%$ of total organic carbon COt,79.50 of $\mathrm{C} / \mathrm{N}, 0.285 \%$ of $\mathrm{K}_{2} \mathrm{O}, 0.264 \%$ of $\mathrm{Na}_{2} \mathrm{O}, 1.504$ $\%$ of $\mathrm{CaO}$, and $0.328 \%$ of $\mathrm{MgO}$. The contents of iron, manganese copper and zinc were, respectively, 0.3, 28.9, 0.5, $2 \mathrm{ppm}$.

The compost used in this study was purchased and then analyzed, it contains $(81.83 \%$ of total organic matter MOt, $47.46 \%$ of organic carbon $\mathrm{CO} \%, 0.1419$ of nitrogen $\mathrm{N}, 0.74 \%$ of total nitrogen $\mathrm{Nt}, 64.15$ of $\mathrm{C} / \mathrm{N}, 0.07 \%$ of total phosphorus Pt, $0.47 \%$ of $\mathrm{K}, 0.08 \% \mathrm{Na}, 3.25 \%$ of $\mathrm{Ca}$ and $0.64 \%$ of $\mathrm{Mg}$ ). Concerning the microelements (Fe, $\mathrm{Mn}, \mathrm{Cu}, \mathrm{Zn}$ ), they were $1556.8,48.1$, 16.3 and 79.3 ppm respectively.

The germination of Paspalum vaginatum grass was done on plastic trays $(33.5 \times 50 \mathrm{~cm})$ containing peat. After 4 weeks, the seedlings were transplanted to a plastic pot (26 cm in height, 12,5 in diameter).

The experiment was conducted on a plastic pot to investigate the efficiency of banana biochar application on a three different water supplies $(100 \%, 80 \%$ and $60 \%)$ in the Paspalum vaginatum grass growth. The plastic pot was filled with $2 \mathrm{~kg}$ of soil, or soil-compost-biochar, soilbiochar, soil-compost mixture according to the following percentage of soil, compost and banana biochar: control (only soil), 2\% compost (C), 2\% biochar (B), 3\% compost (C), 3\% biochar (B), $4 \%$ compost-biochar (BC), $6 \%$ compost-biochar (BC) (control meaning the soil only $100 \%$ of dry soil, 2C meaning soil with $98 \%$ dry soil mixed with $2 \%$ of compost, $2 \mathrm{~B}$ was prepared from $98 \%$ of dry soil and $2 \%$ banana waste biochar, $3 \mathrm{C}$ was contained $97 \%$ of dry soil and 3\% compost, 4BC meaning that $96 \%$ dry soil mixed with $2 \%$ compost and $2 \%$ banana waste biochar, $6 \mathrm{BC}$ made by $94 \%$ of dry soil with $3 \%$ compost and $3 \%$ banana waste biochar). There were three repetitions of each treatment.

In this study, the water holding capacity (WHC) was divided into three categories: $100 \%, 80 \%$, and $60 \%$. In each pot, four juvenile plants were sown. The irrigation was daily for eight weeks. Then, the three water regimes took place, all plants were irrigated twice a week. The growth condition was maintained for one month.

\section{Photosynthesis Measurements}

At the vegetative growth leaf of mature leaves of Paspalum vaginatum from three distinct pots, 
gas-exchange properties were measured using an open system compact infrared gas exchange analyzer (LCi-portable photosynthesis System, ADC, Hertfordshire, UK). The samples were recorded between 9:00 am to 12:00 am. All Paspalum vaginatum grass leaves used for photosynthetic activity measurements were scanned and then the leaf area was calculated using Midebmp software (Ordiales-Plaza, 2000) to convey the outcomes in case of predicted leaf area.

\section{Chlorophyll fluorescence measurements}

Using the OS5p Modulator Fluorometer, we assessed the chlorophyll fluorescence characteristics on three leaves from the same pot treatment in the afternoon in dark and light (ADC BioScientific Ltd, Great Amwell Herts, UK). All leaf samples were kept in dark for 30 minutes before measurements of the activity of photosystem-II.

\section{Chlorophyll pigment}

To extract and analyze pigments, we followed the method reported by Lichtenthaler H.K. et al. [1987]. We measured the contents of chlorophyll $\mathrm{a}$, chlorophyll b, total chlorophyll, and carotenoid in three biological replicates using a UV-1600PC spectrophotometer.

\section{Final Harvest}

After three months, the harvest took place, fresh weight was measured immediately, and the dry weight was calculated after placing leaves and roots biomass of each treatment in the oven for 48 hours in $80^{\circ} \mathrm{C}$.

\section{Multivariate statistical analysis}

We performed a multiple factorial analysis (MFA) on our dataset, which was made up of a set of parameters arranged into groups, in order to identify the relationship between the various types of treatments explored and, eventually, to uncover the impact of the amendment of the mixture of banana biochar and compost from all treatments.

Indeed, MFA is the suitable statistical analysis method, in this case study, since the dataset contains as well quantitative parameters structured in different groups as qualitative variables. The measured parameters were structured into four homogeneous groups such as photosynthesis, chlorophyll fluorescence, chlorophyll pigment, and wet and dry weight. While the categorical group contains the type of treatment and the rate of irrigation.

Furthermore, a two-way ANOVA was used to determine which organic amendment had the greatest effect on physiological parameters in the three water statuses of the Paspalum vaginatum plant. All statistical computations were carried out in RStudio Version 1.4.1717, with the FactoMineR and Factoextra packages (28).

\section{RESULTS}

\section{Physiological measurements}

Multiple factorial analysis was applied for the evaluation of banana waste biochar on physiological traits pigment and growth responses of paspalum vaginatum under three water regimes. The first two dimensions of the MFA (dim1 and $\operatorname{dim} 2$ ) account for about $34 \%$ of the overall inertia, which in this case is sufficient to identify the individuals structure and also the effect of the

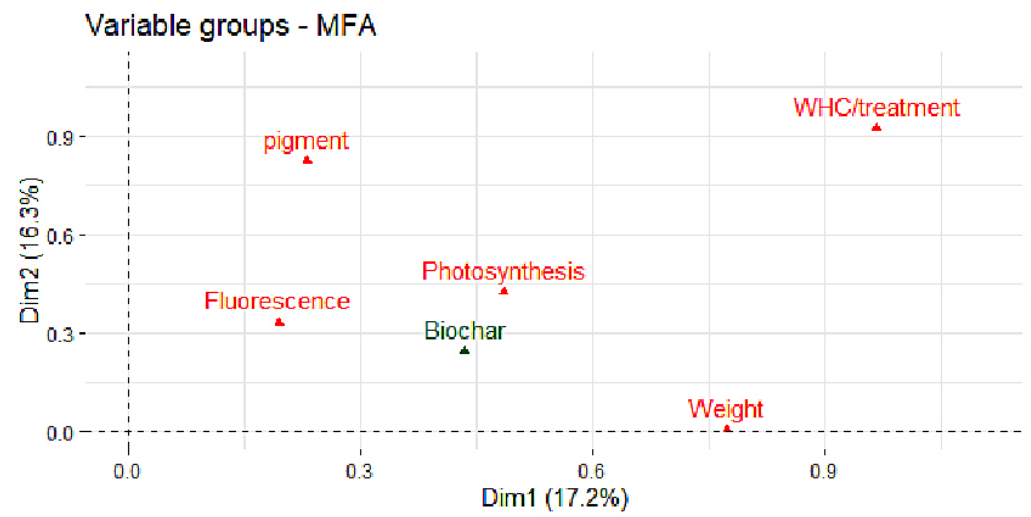

Figure 1. Physiological data from the Paspalum vaginatum Swartz was subjected to multiple factor analysis (MFA). Photosynthesis, fluorescence, WHC/treatment, pigment, and weight are represented as groupings of variables 
different groups of variables on this structure. The five groups of variables coordinates were shown a map of the compound group (Fig. 1).

In terms of the different groups contributions, WHC/treatment has a significant contribution to both axes 1 and $2(\mathrm{RV}=88.17 \%)$. This means that the two modalities (WHC and treatment type) had a highly significant influence on all samples, particularly on the dispersion of the physiological parameter values evaluated.
The group "weight" contributes strongly to MFA axis 1 and not to axis 2. Different conclusions can be drawn regarding the contribution of each group of variables to axis 2. The contribution of pigment appears as to be the most statistically significant, followed by the group "photosynthesis" which had a medium contribution in some treatments to the axis 1 of the MFA and little to the axis 2 . The results will help us to understand the structure of the individuals in the (1-2) design of the

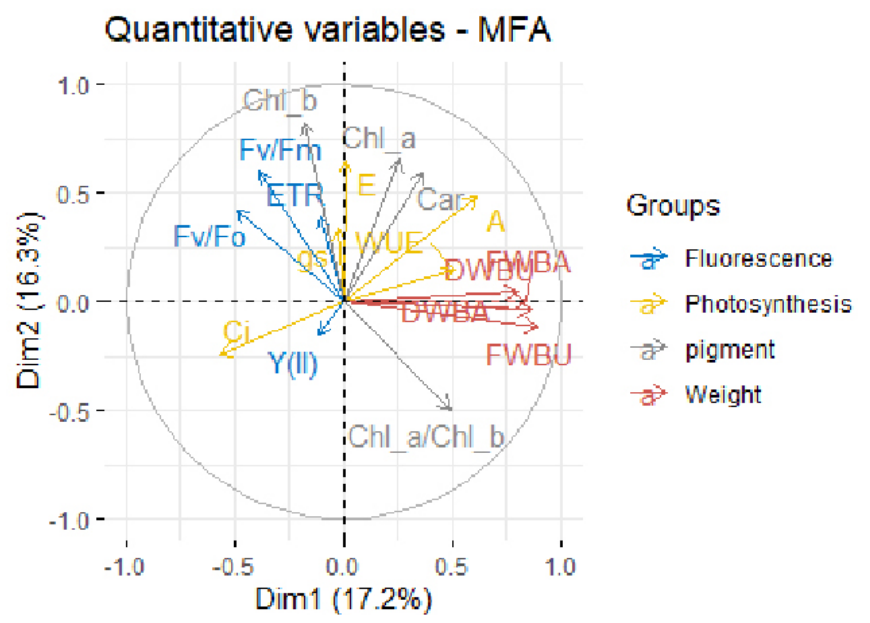

Figure 2. Loading plot describing the variables of treatments of the two-first principal components on the photosynthesis parameters (A: photosynthesis rate, E: transpiration rate, gs: stomatal conductance, and WUE: water- use efficiency), fluorescence parameters (Fv/Fm: maximum photochemical quantum yield of PSII, Fv/Fo: Efficiency of the watersplitting complex on the donor side of PSII, Y(II): effective photochemical quantum yield of PSII, ETR: electron transport rate), pigment (chla:chlorophyll a,chlb: chlorophyll b, chla/b :chlorophyll a/b ratio and car:carotenoids and fresh and dry weight (FWBA: the fresh weight of aerial biomass, FWBU: Fresh weight of underground biomass, DWBA: the dry weight of aerial biomass, DWBU: Dry weight of underground biomass, of the Paspalum vaginatum)

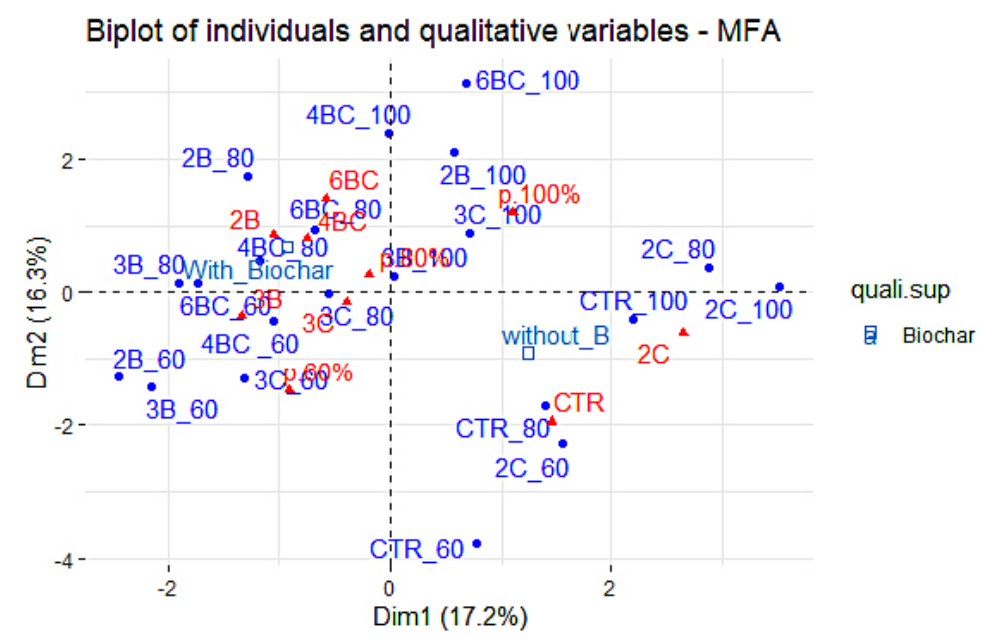

Figure 3. Biplot showing the effect of the banana biochar on the photosynthesis parameters (A: photosynthesis rate, E: transpiration rate, gs: stomatal conductance, and WUE: water- use efficiency), fluorescence parameters (Fv/Fm: maximum photochemical quantum yield of PSII, Fv/Fo: Efficiency of the water-splitting complex on the donor side of PSII, Y(II): effective photochemical quantum yield of PSII, ETR: electron transport rate), pigment (chla:chlorophyll a,chlb: chlorophyll b, chla/b :chlorophyll a/b ratio and car:carotenoids and fresh and dry weight (FWBA: the fresh weight of aerial biomass, FWBU: Fresh weight of underground biomass, DWBA: the dry weight of aerial biomass, DWBU: Dry weight of underground biomass, of the Paspalum vaginatum) 
MFA. With this method,vector and loadings plots display relationships between variables and PCs. In this study, the vector and loadings plots were used to evaluate the effect of banana waste biochar addition on physiological, pigments traits and growth responses of paspalum vaginatum (Fig. 2).

Since the MFA method is considered as a weighted PCA, the correlation coefficients between the variables studied (photosynthesis, fluorescence, pigment characteristics, fresh and dry weight of biomass) and the MFA factorial axes are represented by vectors, whose length and direction are proportional to the values of these coefficients (Fig. 2).
Furthermore, the pattern can be easily explained by the group map and the loading plot. Indeed, the individuals that are on the right of the factorial plan having strong positive coordinates along axis 1 . can be explained by a high irrigation $(100 \%)$ and no amendment (C-control). These samples also have significant weight and photosynthetic characteristics, which clearly distinguishes them from other samples. It should be noticed that the samples on the left with negative values exhibit inverse characteristics (Fig. 3).

On the other hand, the samples at the top of MFA axis 2 are distinguished by high irrigation and a combination of biochar and compost as treatment type. They are also characterized by

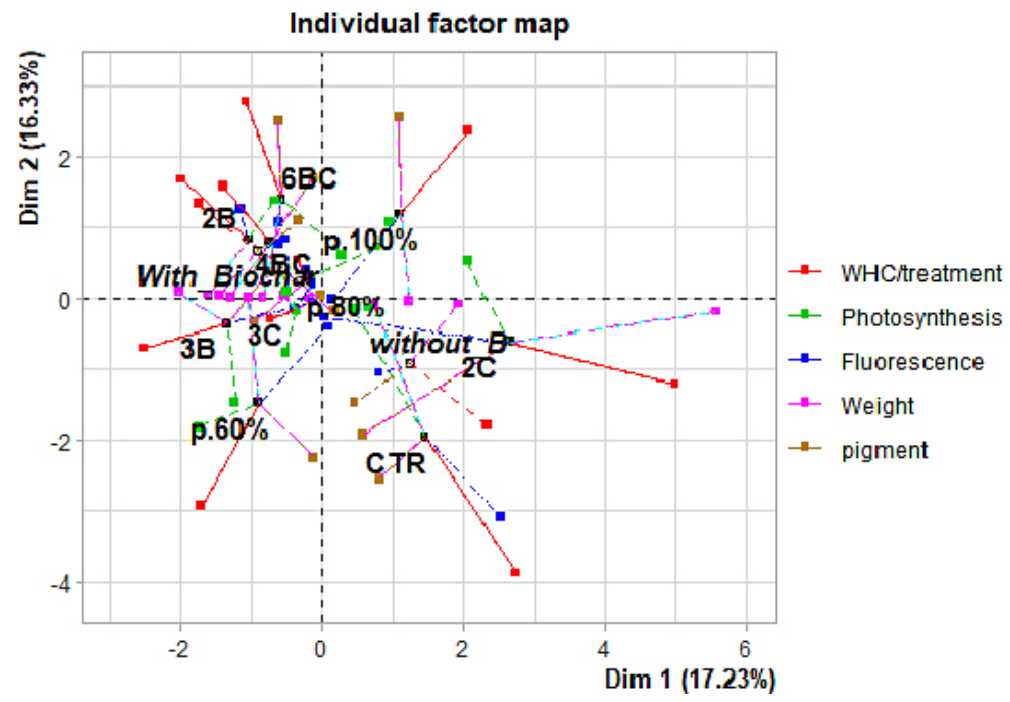

Figure 4. Physiological data in seashore paspalum (Paspalum vaginatum Swartz) plants as modified by three water regimes at 30 DAT using multiple factor analysis (MFA). The twofirst principal components' treatments and groups of variables are depicted in a score plot

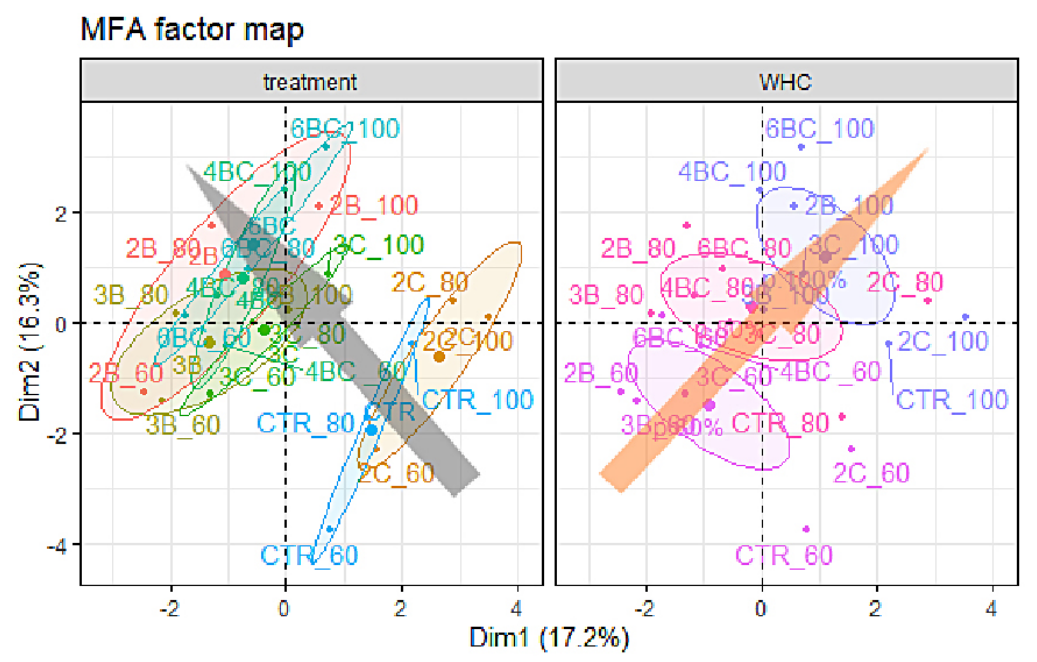

Figure 5. Multiple factor analysis (MFA) of physiological data in seashore paspalum (Paspalum vaginatum Swartz cv. 'SeaSpray') plants as affected by two factors. Score plot describing the treatments and groups of variables of the two-first principal components 
Table 1. Results of two-way ANOVAs with factors biochar (B0, 2, and 3\%), biochar compost combination (4BC and $6 \mathrm{BC} \%$ ) addition and water regimes $(100,80,60 \%)$ on photosynthesis parameters: $\mathrm{A}=$ net photosynthetic rate $\left(\mathrm{mmol} \mathrm{m} \mathrm{s}^{-2}\right), \mathrm{E}=$ transpiration rate $\left(\mathrm{mmol} \mathrm{m} \mathrm{m}^{-2} \mathrm{~s}^{-1}\right), \mathrm{gs}=$ stomatal conductance $\left(\mathrm{mol} \mathrm{m}^{-2} \mathrm{~s}^{-1}\right)$, WUE $=$ water-use efficiency $\left(\mathrm{mmol} \mathrm{m} \mathrm{m}^{-2} \mathrm{~s}^{-1} / \mathrm{mmol} \mathrm{m}^{-2} \mathrm{~s}^{-1}\right)$ fluorecence parameters: ETR= electron transport rate $\left(\mu \mathrm{mol} \mathrm{m} \mathrm{m}^{-2}\right), \mathrm{Fv} / \mathrm{Fm}$ : maximum photochemical quantum yield of PSII and pigment content chlorophyll a $\left(\mathrm{mg}^{\mathrm{g}} \cdot \mathrm{g}^{-1} \cdot \mathrm{FW}\right)$, chlorophyll $\mathrm{b}$ $\left(\mathrm{mg} \cdot \mathrm{g}^{-1} \cdot \mathrm{FW}\right)$, chlorophyll a/b ratio and carotenoids $\left(\mathrm{mg} \cdot \mathrm{g}^{-1} \cdot \mathrm{FW}\right)$

\begin{tabular}{|c|c|c|c|c|}
\hline \multicolumn{2}{|l|}{ Factors } & \multirow{2}{*}{$\begin{array}{c}\text { Treatments } \\
<0.0001\end{array}$} & \multirow{2}{*}{$\frac{\text { WHC }}{<0.0001}$} & \multirow{2}{*}{$\begin{array}{c}\text { Treatments }{ }^{*} \mathrm{WHC} \\
<0.0001\end{array}$} \\
\hline$A\left(u m o l \cdot m^{-2} c^{-1}\right)$ & $p$-value & & & \\
\hline $\mathrm{A}\left(\mu \mathrm{mol} \cdot \mathrm{m}^{-2} \mathrm{~s}^{-1}\right)$ & Fisher-value & 12.2 & 42.4 & 19.2 \\
\hline \multirow{2}{*}{$E\left(m m o l \cdot m^{-2} s^{-1}\right)$} & $p$-value & $<0.0001$ & $<0.0001$ & $<0.0001$ \\
\hline & Fisher-value & 21.78 & 16.9 & 30.42 \\
\hline \multirow{2}{*}{ WUE $\left(\mathrm{mmol} \cdot \mathrm{m}^{-2} \mathrm{~s}^{-1} / \mathrm{mmol} \cdot \mathrm{m}^{-2} \mathrm{~s}^{-1}\right)$} & $p$-value & $<0.0001$ & $<0.0001$ & $<0.0001$ \\
\hline & Fisher-value & 5.586 & 17.413 & 11.511 \\
\hline \multirow{2}{*}{$\mathrm{Gs}\left(\mathrm{mol} \cdot \mathrm{m}^{-2} \mathrm{~s}^{-1}\right)$} & $\mathrm{p}$-value & $<0.0001$ & $<0.0001$ & $<0.0001$ \\
\hline & Fisher-value & 10.84 & 3.89 & 8.03 \\
\hline \multirow{2}{*}{ Ci (vpm) } & $\mathrm{p}$-value & 0.0087 & $<0.0001$ & $<0.0001$ \\
\hline & Fisher-value & 3.35 & 21.29 & 6.60 \\
\hline \multirow{2}{*}{$\operatorname{ETR}\left(\mu \mathrm{mol} \cdot \mathrm{m}^{-2} \mathrm{~s}^{-1}\right)$} & $p$-value & $<0.0001$ & 0.0234 & $<0.0001$ \\
\hline & Fisher-value & 725.8 & 278.9 & 14.1 \\
\hline \multirow{2}{*}{$\mathrm{Fv} / \mathrm{Fm}$} & $p$-value & 0.000583 & 0.080268 & 0.019483 \\
\hline & Fisher-value & 4.35 & 2.58 & 2.15 \\
\hline \multirow{2}{*}{ DWBA (g) } & $p$-value & $<0.0001$ & $<0.0001$ & $<0.0001$ \\
\hline & Fisher-value & 725.8 & 278.9 & 14.1 \\
\hline \multirow{2}{*}{ DWBU (g) } & $\mathrm{p}$-value & $<0.0001$ & $<0.0001$ & $<0.0001$ \\
\hline & Fisher-value & 868.7 & 636.25 & 112.34 \\
\hline \multirow{2}{*}{$\mathrm{Chl}$ a $\left(\mathrm{mg} \cdot \mathrm{g}^{-1} \cdot \mathrm{FW}\right)$} & $\mathrm{p}$-value & 0.001381 & $<0.0001$ & 0.000224 \\
\hline & Fisher-value & 4.47 & 43.27 & 4.25 \\
\hline \multirow{2}{*}{$\mathrm{Chl} \mathrm{b}\left(\mathrm{mg} \cdot \mathrm{g}^{-1} \cdot \mathrm{FW}\right)$} & $\mathrm{p}$-value & $<0.0001$ & $<0.0001$ & $<0.0001$ \\
\hline & Fisher-value & 24.65 & 39.72 & 10.63 \\
\hline \multirow{2}{*}{$\mathrm{Chl}$ a/b ratio } & $p$-value & $<0.0001$ & $<0.0001$ & 0.007 \\
\hline & Fisher-value & 7.91 & 11.02 & 2.79 \\
\hline \multirow{2}{*}{ Carotenoids $\left(\mathrm{mg} \cdot \mathrm{g}^{-1} \cdot \mathrm{FW}\right)$} & $\mathrm{p}$-value & 0.2152432 & $<0.0001$ & 0.0007835 \\
\hline & Fisher-value & 1.46 & 76.54 & 3.70 \\
\hline
\end{tabular}

pigment parameters and in some way by fluorescence and photosynthesis parameters (Fig. 3).

As the first factorial axis (17.23\% inertia) explains variability linked to $\mathrm{WHC} /$ treatment, weight, and photosynthesis, while the second axis $(16.33 \%$ inertia) indicates fluorescence and pigment performance.

Overall, treatments amended with biochar and compost yielded high levels of fluorescence and pigment, particularly $2 \mathrm{~B}, 3 \mathrm{~B}$, and $4 \mathrm{BC}$. In general, the treatments mostly on top have been high in pigment and had high photosynthesis and fluorescence activities. In contrast, the three treatments $2 \mathrm{C} 80,2 \mathrm{C} 100$, and CTR 100 had high values of weight (DWBA,DWBU), A, and WUE, but low values of $\mathrm{Ci}$. The lowest treatment was CTR 60, which meant that the soil only had $60 \% \mathrm{WHC}$, resulting in low values of physiological activity and weak paspalum growth
(Fig. 3). Further, Figure 4, named the individual factor map, depicts the connection between the category group (WHC/treatment) and the physiological indicators. Hence, the black dots that indicate the treatment kinds are the barycenter of the colored dots corresponding to the measured parameters. Hence, the treatments located at right had a low value of weight, and physiological parameters. In contrast, the treatments amended with biochar and compost addition had revealed a high responses of gas exchange and a heavy biomass.

The factor map provided by the MFA (Fig. 5) highlighted the overall effects of the treatments and water-holding capacity obtained through the experience of the physiological and pigment data. Indeed, the diagonal line of the right-hand plot of figure 5 reflects the evolution of irrigation from bottom left to top right 
Table 2. Results of Scheffe test means of different treatments under three water supplies (100, 80, 60\%) on photosynthesis, fluorescence, fresh and dry weight of Paspalum vaginatum

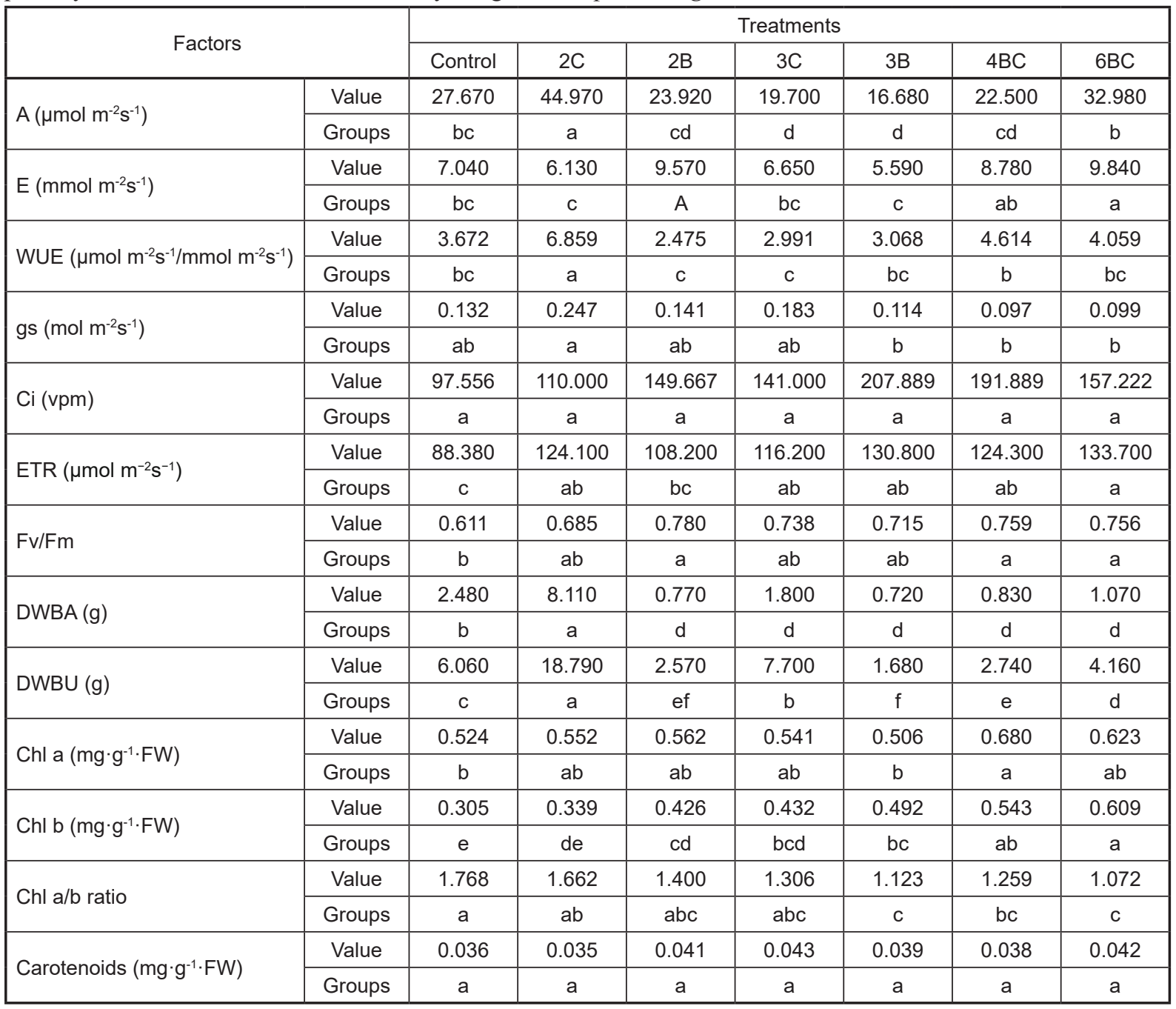

$(60 \%$ to $100 \%)$. While the diagonal of the left plot reflects the role of addition of the amendment. The combination of biochar and compost had led to a high photosynthetic values and weight even in treatments irrigated at $80 \%$ and $60 \%$ water supplies, especially for the treatments 6BC_80, and 4BC_80. Both WHC and the type of treatment successes to show that amending soil with the combination of biochar and compost can provide the same result as the treatment irrigated with $100 \%$ of water supply. With the different addition of organic amendments (biochar, compost or biochar and compost combination), seashore paspalum exhibited a significant result on growth responses, physiological traits and pigment (Table 1). Banana biochar application had positive effect on variables observed on all treatments. Almost all of the variables in Table 1 have extremely significant effects on A, E, WUE, gs,
Ci, ETR, DWBA, DWBU, and chlorophyll b (p-value $<0.0001$ ).

The purpose of the present study is to compare the different banana waste biochar effects on physiological traits and growth responses on seven treatments: control , 2C, 2B, 3C, 3B, $4 \mathrm{BC}$ and $6 \mathrm{BC}$. The two ways analysis of variance was followed by a Scheffe test to conduct a pairwise comparison of means; Table 2 summarizes the results of this comparison. In comparison to the control, banana waste biochar and compost combinations (4BC and 6BC) showed the highest levels of transpiration (E), photosynthetic rate (A), water-use efficiency (WUE), and electron transport rate (ETR). In contrast, for dry weight of aerial biomass (DWBA) and dry weight of underground biomass (DWBU), significantly were higher with treatments amended with $2 \%$ compost $(2 \mathrm{C}$ ) comparing with others. 


\section{DISCUSSION}

The $2 \%$ compost treatment under $100 \%$ and $80 \%$ water regimes $\left(2 \mathrm{C} \_100\right.$ and $\left.2 \mathrm{C} \_80\right)$ showed high values of photosynthetic parameters (A, E and WUE) and a high weight of the fresh and dry weight of aerial and underground biomass. [Amiri et al., 2017] reported that adding vermicompost enhances WUE. Banana biochar-compost addition at $4 \%(4 \mathrm{BC})$ was the best treatment to improve WUE in $60 \%$ water supply, while in $80 \%$ and $100 \%$ water regimes, $4 \mathrm{BC}$ showed a little improvement in WUE comparing to the control. Our results showed that combining biochar with compost enhance WUE of paspalum vaginatum even in a $60 \%$ water regime, however, $6 \mathrm{BC}$ had shown an efficient enhancement especially in $100 \%$ and $80 \%$ water treatments and not in $60 \%$, which was surprising. Furthermore, the treatment $2 \mathrm{C}$ had the more efficient effect of stomatal conductance comparing to others. In comparison with our results, [Abideen et al., 2020] found that biochar improved photosynthetic activity and chlorophyll fluorescence. Vaughn et al. [2018] reported that adding biochar and compost mixtures as an amendment for golf courses had the greatest fresh weights, dry weights, shoot heights of bentgrass compared to the $15 \%$ peat control. For $2 \mathrm{~B}$ and $3 \mathrm{~B}$ treatments, WUE revealed a certain increase in $100 \%$ and $80 \%$ water regimes. In this sense, Haider et al. [2015] found that water-use efficiency was improved in $1.5 \%$ biochar addition and not in 3\% biochar addition. They argue that there is a lot of reasons that can affect the 3\% Biochar addition like the immobilization /adsorbed mineral-N. Moreover, the study of Uzoma et al. [2011] based on cow manure biochar addition on maize production revealed that WUE was improved, with the 10,15 , and $20 \mathrm{t} / \mathrm{ha}$ mixing rate, which is in line with our results (2\% Biochar and 3\% Biochar correspond to $41.43 \mathrm{t} / \mathrm{ha}$ and $62.15 \mathrm{t} / \mathrm{ha}$ respectively). Even if the irrigation was $100 \% \mathrm{WHC}$, the wateruse efficiency of paspalum vaginatum was not strong enough which means that the grass doesn't need a huge quantity of water. We can understand that giving a huge quantity of water didn't mean that the plant will grow better. However, with irrigation of $60 \%$ and $80 \%$ water regimes and an amendment with banana biochar and compost, the paspalum vaginatum takes a sufficient quantity of water as well as the mineral and organic nutrients benefits for the plant growth. We noticed that the highest value was from $2 \%$ compost soil irrigated at $80 \%$ treatment followed by $4 \%$ banana biochar compost soil treatment irrigated by $60 \%$.

Amending treatments with compost alone or with biochar as a single application (2C 100, 2C 80 , 2B 100, and 2B 80), Paspalum vaginatum requires more water for root development. In our case, we irrigated each pot of paspalum vaginatum twice a week with $100 \%$ and $80 \%$, which correspond to $83 \mathrm{ml}$ and $66 \mathrm{ml}$ of water respectively. While in amending with biochar and compost, seashore paspalum tended to accept less water and a great response of fresh and dry weight, photosynthetic and fluorescence activities. In our study, 6BC_60 and 4BC_60 treatments had a significant responses of growth. Unlike a single addition of organic amendment, which requires a greater amount of water, compost can supply nutrients and biochar can retain them in its pores to provide them to the plant which is in line with the finding of Vaughn et al. [2018].

Indeed, fluorescence parameters represent the tool of the stressed plant. The $(\mathrm{Fv} / \mathrm{Fm})$ was highly with the amended treatments but not with the unmodified treatments. Also this parameter synchronizes all photochemical phase as well as photon trapping events. Furthermore, it is mutually related to $\mathrm{Fv} / \mathrm{Fo}$, which is regarded as an affirmation of a effectiveness of the moisture system. (Kalaji et al., 2012), (Bussotti et al., 2020).

The variables of fluorescence could really represent a number of significant regulations in the photosynthesis process system [Zhang et al., 2019]. In the paspalum vaginatum growing, the values of $\mathrm{Fv} /$ Fm for all treatments were significantly higher expect the control at 60\% water regime (ctr_60). For the ETR, and Y(II), were significantly higher for the 3\% biochar treatment in $60 \%$ water regime than the other treatments, indeed, the four fluorescence parameters (Fv/Fm, Fv/Fo, ETR, and Y(II)) of the biochar treatments had little change over the whole growth in the three different water regimes. In that concern, Water scarcity, according to Haider et al. [2015], can have a detrimental effects on photosynthetic activity leading to a decline in ETR and Y(II).

$\mathrm{Y}$ (II) and the photosynthetic electron transport activity of rice leaves diminishes under water stress, according to Xu et al. [2020], which is consistent with our findings, which showed low ETR and $\mathrm{Y}$ (II) values in the control treatment irrigated at $60 \%$. In our case, $60 \%$ WHC was considered the minimum quantity of plant irrigation. Paspalum vaginatum had developed roots during the $60 \% \mathrm{WHC}$ in the third group treatments, the fresh 
weight of underground biomass was greater also with 4BC_60 and 6BC_60. Our results are consistent to those studies of the Huang et al. [1997] and Zhang et al. [2019], who assumed that root growth is crucial for drought stress in turfgrasses. Besides, the growth of strong roots and their length density has earlier become linked to greater drought resistance [Marcum et al., 1995].

Environmentally, the parameters of treatments amended with compost and biochar appear to be linked to great climate factors for plants growth, owing to the combination of biochar and compost with a small amount of water. This organic amendment combination allowed for the complete construction of fluorescence machinery and growth.

The treatment amended by $2 \%$ compost and irrigated with $100 \%$ of $\mathrm{WHC}$ had revealed a high response of photosynthesis rate and stomatal conductance with $100 \mu \mathrm{mol} \cdot \mathrm{m}^{-2} \mathrm{~s}^{-1}$ and $0.3 \mathrm{~mol} \cdot \mathrm{m}^{-2} \mathrm{~s}^{-1}$ respectively. The same response was noticed with the treatments amended with $2 \%$ compost and irrigated with $80 \%$ water regime. According to Singh and Raja Reddy [2011], gs responded to almost all various factors associated with photosynthetic parameters in general, which is consistent with our findings ( $2 \%$ Compost at $100 \%$ and $80 \%$ of WHC).

Changes in gas exchange have been found to be closely dependent on water condition in several species of plants [Yan et al., 2016]. Optimizing photosynthesis as well as stomatal conductance during abiotic stresses is essential for plant species to preserve carbohydrate production and diminish evaporation in order to stay alive in arid zones.

Chlorophylls reveals remarkably similar responses to our pigment measurements.Generally, all treatments irrigated with $100 \%$ of water supply were showed higher concentrations of Chlorophyll a and Chlorophyll $\mathrm{b}$ whereas the treatment irrigated with $80 \%$ and $60 \%$ exhibited a lower reply treatments amended with banana biochar and compost combination (6BC) had high values of pigment compared to the control plants.

A similar result was observed in carotenoids content (car), where the $4 \mathrm{BC}$ and $6 \mathrm{BC}$ treatments of the three water regimes outperformed the other treatments. Sum up, the $\mathrm{Chl} \mathrm{a} / \mathrm{b}$ ratio profiles closely reflects the control in three water supplies. The $4 \mathrm{BC}$ and $6 \mathrm{BC}$ treatments had no effect on the $\mathrm{Chl} \mathrm{a} / \mathrm{b}$ ratio. The $3 \mathrm{C}$ and $3 \mathrm{~B}$ revealed significant decrease in the $\mathrm{Chl} \mathrm{a} / \mathrm{b}$ ratio at 80 percent water supply. The decrease of $\mathrm{Chl} \mathrm{b}$ was higher than that of $\mathrm{Chl}$ a under drought stress. This significant decrease might be clarified by changing the proportion against $\mathrm{Chl}$ a. [Jaleel et al., 2009; Jain et al., 2010 and Ashraf et al., 2013].

MFA aided in the analysis of a set of observations based on pigment content, fluorescence, and leaf gas exchange data in this study, providing an accurate image of the observational data and the connections between the factors registered at the study. The analysis led to the gradual separation of the entries as affected by banana waste biochar as a singular addition and combined with compost. Moreover, the use of the multicanonical analysis highlighted the presence of specific groups (the high values with the compost and banana waste biochar addition, the treatments amended with compost or biochar as singular and irrigated at $100 \%$ or $80 \%$, and the group of control which had a low physiological activities.

\section{CONCLUSION}

In sum, our findings revealed the main responses of Paspalum vaginatum to three distinct regimes, depending on the effect of banana biochar and compost.The results obtained in this study indicated that the two treatments (4BC and $6 \mathrm{BC}$ ) had a greater response of the photosynthetic and morphological apparatus to maintain a high quality of seashore paspalum with a minimum quantity of water. However, the paspalum vaginatum tended to a negative effect, mainly through the increase of the chl a/b ratio, and a decrease of fresh weight of roots with the control treatment with the three water supplies. Under these conditions, the management of luxury golf courses could be expanded at a better price. As fresh water exhaust caused by rapid urban and global climate change, the use of a biochar and compost mixture for turf irrigation purposes will be required. Future field tests for severe drought would provide a thorough explanation for Paspalum vaginatum's responses in arid and semi-arid zones.

\section{Acknowledgments}

The current research was supported by the Laboratory of Biotechnology, Materials and Environment of the Faculty of Sciences of Agadir, the Polydisciplinary Faculty of Taroudant, and the Faculty of Applied Sciences of Ait Melloul, University Ibn Zohr. The author would like to thank also CNRST scholarship (National Center for Scientific and Technical Research in Morocco). 


\section{REFERENCES}

1. Carrow R.N. 1995. Drought Resistance Aspects of Turfgrasses in the Southeast, Evapotranspiration and Crop Coefficients. Crop Sci., 35, 1685-1690.

2. Katuwal K.B., Tishchenko V, Jespersen D. 2020. Assessing drought resistance in seashore paspalum genotypes using leaf gas exchange, osmotic adjustment, and rooting characteristics. Crop Sci., 61, 1-14.

3. Dean D.E., Devitt D.A., Verchick L.S., Morris R.L. 1996. Turfgrass quality, growth, and water use influenced by salinity and water stress. Agron. J., 88, 844-849.

4. Fetjah D., Ainlhout L.F.E., Ihssane B., Houari A., Idardare Z., Bouqbis L. 2021. Biological, physico-chemical and morphological analyses of four biochars derived from agricultural waste. Journal of Ecological Engineering, 22(4), 36-46.

5. Frascari D., Zanaroli G., Motaleb M.A., Annen G., Belguith K., Borin S., et al. 2018. Integrated technological and management solutions for wastewater treatment and efficient agricultural reuse in Egypt, Morocco, and Tunisia, Solutions for Wastewater Treatment and Reuse in North Africa. Integr. Environ. Assess. Manag., 14, 447-462.

6. Bezerra J., Turnhout E., Vasquez I.M., Rittl T.F., Arts B., Kuyper T.W. 2019. The promises of the Amazonian soil, shifts in discourses of Terra Preta and biochar J. Environ. Policy Plan., 21, 623-635.

7. Rasa K., Heikkinen J., Hannula M., Arstila K., Kulju S., Hyväluoma J. 2018. How and why does willow biochar increase a clay soil water retention capacity? Biomass Bioenergy. 119, 346-353.

8. Ibitayo O.O., Bulter J.D., Burke M.J. 1981. Cold hardiness of bermudagrass and Paspalum vaginatum Sw. HortScience. 16, 683-684.

9. Bouqbis L., Koyro H.W., Harrouni M.C. 2016. Daoud S., Ainlhout L.F.Z., Kammann C.I. Effect of Two Different Biochars on Germination and Seedlings Growth of Salad, Cress and Barley. Int. J. Agric Biosyst. Eng., 10, 872-880.

10. Lichtenthaler H.K. 1987. Chlorophylls and carotenoids, Pigments of photosynthetic biomembranes. Methods Enzymol. 148, 350-382.

11. Abideen Z, Koyro H.W., Huchzermeyer B., Ansari R., Zulfiqar F., Gul B. 2020. Ameliorating effects of biochar on photosynthetic efficiency and antioxidant defence of Phragmites karka under drought stress. Plant Biol J., 22, 259-266.

12. Vaughn S.F., Dinelli F.D., Jackson M.A., Vaughan M.M., Peterson S.C. 2018. Biochar-organic amendment mixtures added to simulated golf greens under reduced chemical fertilization increase creeping bentgrass growth. Ind Crops Prod., 111, 667-672.

13. Amiri H., Ismaili A., Hosseinzadeh S.R. 2017. Influence of Vermicompost Fertilizer and Water Deficit Stress on Morpho-Physiological Features of Chickpea (Cicer arietinum L. cv. karaj). Compost Sci Util., $25,152-165$.
14. Haider G., Koyro H.W., Azam F., Steffens D., Müller C., Kammann C. 2014. Biochar but not humic acid product amendment affected maize yields via improving plantsoil moisture relations. Plant Soil., 395, 141-57.

15. Uzoma K.C., Inoue M., Andry H., Fujimaki H., Zahoor A., Nishihara E. 2011. Effect of cow manure biochar on maize productivity under sandy soil condition, Cow manure biochar agronomic effects in sandy soil. Soil UseManage., 27, 205-212.

16. Kalaji H.M., Carpentier R., Allakhverdiev S.I., Bosa K. 2012. Fluorescence parameters as early indicators of light stress in barley. J. Photochem. Photobiol. B., 112, 1-6.

17. Bussotti F., Gerosa G., Digrado A., Pollastrini M. 2020. Selection of chlorophyll fluorescence parameters as indicators of photosynthetic efficiency in large scale plant ecological studies. Ecol. Indic., 108, 1-10.

18. Zhang J., Poudel B., Kenworthy K., Unruh J.B., Rowland D., Erickson J.E., et al. 2019. Drought responses of above-ground and below-ground characteristics in warm-season turfgrass. J. Agron. Crop. Sci., 205, 1-12.

19. Xu Q., Ma X., Lv T., Bai M., Wang Z., Niu J. 2020. Effects of Water Stress on Fluorescence Parameters and Photosynthetic Characteristics of Drip Irrigation in Rice. Water. 12, 289-308.

20. Huang B., Duncan R.R., Carrow R.N. 1997. Drought-resistance mechanisms of seven warm-season turfgrasses under surface soil drying, I. Shoot Response. Crop Sci., 37, 1858-1863.

21. Marcum K.B., Engelke M.C., Morton S.J., 1995. White RH. Rooting Characteristics and Associated Drought Resistance of Zoysiagrasses. Agron. J., 87, 534-538.

22. Carrow R.N. 1996. Drought Resistance Aspects of Turfgrasses in the Southeast, Root-Shoot Responses. Crop Sci. 36, 687-694.

23. Singh S.K., Raja Reddy K. 2011. Regulation of photosynthesis, fluorescence, stomatal conductance and water-use efficiency of cowpea (Vigna unguiculata [L.] Walp.) under drought. J. Photochem. Photobiol. B., 105, 40-50.

24. Medrano H., Escalona J.M., Bota J., Gulias J., Flexas J. 2002. Regulation of Photosynthesis of C3 Plants in Response to Progressive Drought, Stomatal Conductance as a Reference Parameter. Ann Bot. 89, 895-905.

25. Yan W., Zhong Y., Shangguan Z. 2016. A meta-analysis of leaf gas exchange and water status responses to drought. Sci Rep., 6, 1-9.

26. Jaleel C.A., Manivannan P., WahidA., Farooq M., Al-Juburi J., Somasundaram R., et al. 2009. Drought stress in plants, a review on morphological characteristics and pigments composition. Int. J. Agric. Biol., 11, 100-105.

27. Jain M., Tiwary S., Gadre R. 2010. Sorbitol-induced changes in various growth and biochemical parameters in maize. Plant Soil Environ., 56, 263-267.

28. Ashraf M, Harris P.J.C. 2013. Photosynthesis under stressful environments, An overview.Photosynthetica., 51, 163-190.

29. Lê S., Josse J., Husson F. 2008. FactoMineR, An R Package for Multivariate Analysis. Journal of Statistical Software. 25(1), 1-18. 